\section{Bê tông Geopolymer sử dụng cốt liệu tái chế: nghiên cứu một số phương pháp xử lý cốt liệu}

\author{
Nguyễn Ngọc Hoàng ${ }^{1,2}$, Bùi Quốc Bảo ${ }^{1}$, Lưu Thị Hồng ${ }^{3 *}$ \\ ${ }^{1}$ Khoa Kỹ thuật Công trình, Trường Đại học Tôn Đức Thắng, TP. Hồ Chí Minh \\ ${ }^{2}$ Phòng Quản lý xây dựng, Sở Xây dựng tỉnh Bình Phước, Đồng Xoài, Bình Phước \\ ${ }^{3}$ Viện Vật liệu Xây Dựng, Ngõ 235 Nguyễn Trãi, phường Thanh Xuân Trung, quận Thanh Xuân, Tp. Hà Nội
}

TỪ KHOÁ

Cốt liệu bê tông tái chế (CLTC)

Bê tông geopolymer cốt liệu tái chế

Tro bay

Nước vôi

Cường độ chịu nén

\section{KEYWORDS}

Recycled concrete aggregate (RCA)

Geopolymer recycled aggregate

concrete (GRAC)

Fly ash

Limewater

Compressive strength

\section{TÓM TÁ́T}

Trong bối cảnh phế thải xây dựng phát sinh ngày càng nhiều, cùng với đó lượng tro bay, xỉ thải ra từ các nhà máy nhiệt điện còn ít được tái sử dụng, đặt ra yêu cầu cấp thiết đối với ngành xây dựng phải có giải pháp xử lý đồng bộ, tái chế các loại vật liệu để sản xuất vật liệu xây dựng, góp phần bảo vệ môi trường, tiết kiệm nguồn tài nguyên. Bài báo này trình bày nghiên cứu sử dụng cốt liệu bê tông tái chế (CLTC) thay thế hoàn toàn đá tự nhiên, và các biện pháp xử lý CLTC. Tro bay và các dung dịch hoạt hoá (NaOH và $\mathrm{Na}_{2} \mathrm{SiO}_{3}$ ) đã được sử dụng để tạo ra chất kết dính geopolymer thay thế xi măng truyền thống. Các thành phần bê tông geopolymer với các trạng thái CLTC khác nhau đã được nghiên cứu: CLTC khô, CLTC bão hoà nước và CLTC bão hoà nước vôi. Bê tông xi măng đá tự nhiên cũng đã được sản xuất để đối chứng. Cấu trúc vi mô của vật liệu được quan sát bằng phương pháp SEM (Scanning Electron Microscope). Kết quả cho thấy việc xử lý CLTC bằng cách ngâm trong nước vôi cải thiện đáng kể tính chất cơ học của bê tông Geopolymer sử dụng hoàn toàn CLTC: cường độ chịu nén tăng gấp 2 đến 3 lần so với mẫu bê tông sử dụng CLTC ở trạng thái khô và trạng thái bão hòa nước, đồng thời đạt khoảng $80 \%$ so với mẫu bê tông xi măng truyền thống. Các kết quả này mở ra tiềm năng ứng dụng của bê tông geopolymer CLTC.

\section{ABSTRACT}

On one hand, the construction demolition wastes have constantly increased. On the other hand, the quantity of fly ash from the coal power plants have also significantly increased which need to be valorised. This context requests the construction industry to recycle these materials in the production of construcion materials, that contributes to the preservation of the environment and natural resources. This paper presents a study on the use of recycled concrete aggregate (RCA) to replace coarse aggregates, and on the treatment methods of RAC. Fly ash was activated by an alkaline activator solution (sodium silicate and sodium hydroxide) to create a geopolymer binder which substitutes the Portland cement. Geopolymer recycled aggregate concrete (GRAC) with RCA from different pre-treated states were investigated: dry, water saturated and lime water saturated. The ordinary cement concrete with natural aggregates was also manufactured for the comparison. The microstructure was investigated by the SEM (Scanning Electron Microscope) technique. The results showed that samples with RAC pre-treated by lime water significantly improved the the compressive strength 2 to 3 times when compared to samples using RAC without pre-treatment or pre-treated by water. These results are positive which show the potential for the application of GRAC.

\section{Giới thiệu}

Ngày nay, ngành công nghiệp xây dựng đang sử dụng một lượng lớn các nguồn tài nguyên thiên nhiên và năng lượng, bê tông xi măng là một trong những vật liệu được sử dụng rộng rãi trong các công trình xây dựng dân dụng và công trình hạ tầng kỹ thuật. Theo thống kê của Bộ Xây dựng, trong năm 2019, Việt Nam sử dụng khoảng 140 triệu m³ bê tông, trong gần 20 năm qua, do lượng xây dựng kết cấu hạ tầng tăng trưởng mạnh nên sản lượng xi măng sử dụng đã tăng tới 6 lần, từ 17 triệu tấn/năm lên 98 triệu tấn/năm [1], ngành sản xuất xi măng có lượng phát thải khí nhà kính chiếm khoảng 88,8 \% tổng lượng phát thải của sản xuất công nghiệp, đây là ngành sử dụng rất nhiều năng lượng và tạo ra nhiều khí thải do đòi hỏi nhiệt độ cực cao [2].

Hiện nay, tro bay là một trong những loại vật liệu đang được quan tâm nghiên cứu có thể thay thế xi măng truyền thống trong chế tạo bê tông geopolymer. Tro bay là phế thải của các nhà máy nhiệt điện, ước tính cả nước đang có khoảng 25 nhà máy nhiệt điện đã đi vào vận hành thương mại, lượng tro, xỉ tại phát sinh thực tế khoảng 13 triệu tấn/năm 
[3], được tích trữ tại các bãi chứa, hồ chứa từ nhiều năm nay. Cùng với đó, việc xây dựng, cải tạo nâng cấp và phá dỡ các công trình cũ sẽ thải ra lượng lớn phế thải xây dựng (PTXD). Chất thải rắn xây dựng chiếm khoảng 20 đến $25 \%$ chất thải sinh hoạt [4]. Lượng phế thải này mặc dù phát sinh ngày càng nhiều nhưng chưa được tái chế hay sử dụng một cách hợp lý [5]. Việc nghiên cứu tận dụng cốt liệu bê tông tái chế (CLTC) để chế tạo bê tông geopolymer là hướng nghiên cứu đang được quan tâm nghiên cứu trên thế giới cũng như ở Việt Nam [6].

Vật liệu Geopolymer được nghiên cứu từ những năm 1970, đến năm 1978, nhà hoá học người Pháp Joseph Davidovits chế tạo thành công loại vật liệu được gọi là "Geopolymer" theo một quy trình tổng hợp polymer từ các khoáng chất, bằng cách kích hoạt các chất chứa silic oxide và nhôm oxide bằng dung dịch alkali silicates có nồng độ kiềm cao, hỗn hợp này có chất nền là silic oxide, xút và kali [7]. Công nghệ này nhanh chóng được phát triển trên toàn thế giới và đang dần dần có ưu thế hơn xi măng Porland do có ưu điểm về nguyên liệu sản xuất, và geopolymer có lượng phát thải $\mathrm{CO}_{2}$ ít hơn so với xi măng Porland truyền thống. Bê tông Geopolymer có các đặc tính cơ lý có thể thay thế được bê tông xi măng truyền thống. Từ đó, nhiều nghiên cứu về bê tông Geopolymer đã được thực hiện [8].

Trên thế giới, trong khi đã có nhiều nghiên cứu về bê tông geopolymer sử dụng cốt liệu tự nhiên hoặc bê tông xi măng sử dụng cốt liệu tái chế, thì số lượng các nghiên cứu về bê tông geopolymer sử dụng cốt liệu tái chế vẫn còn hạn chế. Các nghiên cứu trước đây đã đánh giá một số yếu tố như các đặc tính cơ học của bê tông geopolymer cốt liệu tái chế bằng các thay đổi thành phần các chất tạo nên geopolymer như dung dịch kiềm hoạt hoá, chất cần kích hoạt như tro bay, xỉ lò cao, cũng như tỉ lệ CLTC trong hỗn hợp bê tông [6, 9, 10]. Tuy nhiên, các nghiên cứu về việc cải thiện chất lượng CLTC nhằm nâng cao các đặc tính cơ học của bê tông Geopolymer vẫn còn chưa được được nhắc đến. Thực vậy, do hạt CLTC có độ rỗng lớn, độ hút nước lớn, cường độ cơ học thấp, có nhiều tạp chất bám trên bề mặt hạt cốt liệu nên làm giảm mối liên kết giữa xi măng và cốt liệu, dẫn đến chất lượng bê tông sử dụng CLTC thấp. Vì vậy việc nghiên cứu cải thiện chất lượng CLTC trước khi chế tạo bê tông geopolymer là rất quan trọng.

Bài báo này trình bày một ý tưởng nâng cao chất lượng của bê tông Geopolymer sử dụng 100 \% CLTC với giải pháp ngâm CLTC trong nước vôi. Cường độ chịu nén của các mẫu bê tông đã được thực hiện và đánh giá, so sánh với các mẫu đối chứng (mẫu bê tông sử dụng 100 \% CLTN), cũng như của các nghiên cứu đã được thực hiện trước đây.

\section{Vật liệu và thí nghiệm}

\subsection{Vật liệu sử dụng}

\subsubsection{Tro bay}

Tro bay được sử dụng trong nghiên cứu này có nguồn gốc từ nhà máy nhiệt điện Duyên Hải III (Hình 1). Thành phần hóa học của tro bay được thể hiện ở Bảng 1. Theo Tiêu chuẩn TCVN 10302:2014 [11], tro bay được sử dụng thuộc loại $\mathrm{F}$. Hàm lượng các chất nhôm oxit, silic oxit và sắt oxit trong tro bay $>70 \%$. Hàm lượng $\mathrm{SiO}_{2}$ và $\mathrm{Al}_{2} \mathrm{O}_{3}$ trong tro bay là cao, thể hiện khả năng có thể được kích hoạt để tạo thành geopolymer.

Bảng 1. Thành phần hóa học của tro bay.

\begin{tabular}{|l|l|l|l|l|l|l|l|l|}
\hline Thành phần hóa học & $\mathrm{SiO}_{2}$ & $\mathrm{Al}_{2} \mathrm{O}_{3}$ & $\mathrm{FeO}$ & $\mathrm{CaO}$ & $\mathrm{MgO}$ & $\mathrm{Na}_{2} \mathrm{O}$ & $\mathrm{K}_{2} \mathrm{O}$ & $\mathrm{SO}_{3}$ \\
\hline Theo khối lượng (\%) & 51,17 & 22,58 & 9,90 & 5,94 & 2,56 & 3,23 & 2,58 & 2,04 \\
\hline
\end{tabular}

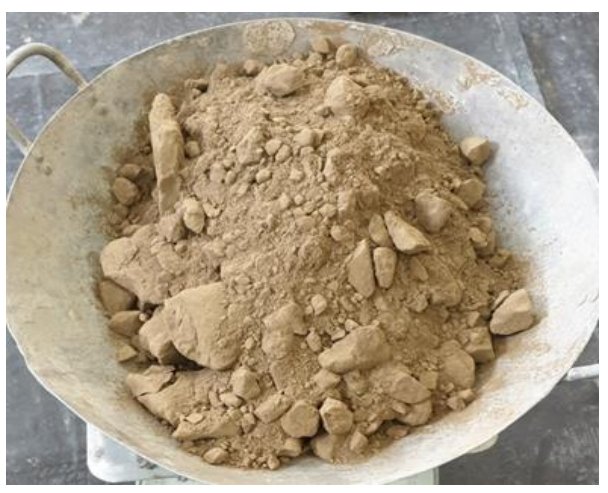

(a) Tro bay

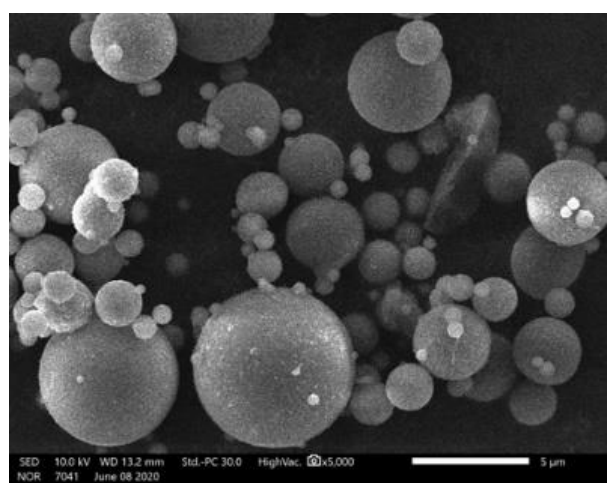

(b) Cấu trúc vi mô tro bay

Hình 1. Hình dạng tro bay được sử dụng.

\subsubsection{Dung dịch kiềm hoạt hóa}

Dung dịch kiềm hoạt hóa có vai trò là chất kích hoạt $\mathrm{SiO}_{2}$ và $\mathrm{Al}_{2} \mathrm{O}_{3}$ trong tro bay để tạo thành chất kết dính geopolymer. Dung dịch kiềm hoạt hóa được sử dụng trong nghiên cứu này là sự kết hợp giữa dung dịch $\mathrm{Na}_{2} \mathrm{SiO}_{3}$ và dung dịch $\mathrm{NaOH}$ với tỉ lệ dung dịch $\mathrm{Na}_{2} \mathrm{SiO}_{3} / \mathrm{NaOH}$ là 2,5 [12]. Dung dịch $\mathrm{Na}_{2} \mathrm{SiO}_{3}$ có thành phần là $11,8 \% \mathrm{Na}_{2} \mathrm{O}, 29,5 \% \mathrm{SiO}_{2}$, và $58,7 \%$ nước. Dung dịch $\mathrm{NaOH}$ được chế tạo bằng cách hòa tan các tinh thể rắn $\mathrm{NaOH}$ trong nước cất. Nghiên cứu sử dụng dung dịch $\mathrm{NaOH}$ có nồng độ Mol là $10 \mathrm{M}$, theo kết quả một nghiên cứu tối ưu hoá thành phần cho vữa geopolymer [6]. Tỉ lệ dung dịch kiềm hoạt hóa/tro bay sử dụng trong nghiên cứu là 0,5 . Thành phần chất hoạt hóa kiềm trong $1 \mathrm{~m}^{3}$ bê tông theo Bảng 2 . 
Bảng 2. Thành phần dung dịch kiềm hoạt hóa trong $1 \mathrm{~m}^{3}$ bê tông.

\begin{tabular}{|c|c|c|}
\hline Tro bay $(\mathrm{kg})$ & Dung dịch $\mathrm{Na}_{2} \mathrm{SiO}_{3}(\mathrm{~kg})$ & Dung dịch $\mathrm{NaOH}(\mathrm{kg})$ \\
\hline 350 & 125 & 50 \\
\hline
\end{tabular}

\subsubsection{Cốt liệu bê tông tái chế}

CLTC được sử dụng có nguồn gốc từ phế thải của cấu kiện bê tông mác M250, được thu gom từ việc phá dỡ công trình xây dựng nhà ở. CLTC được sử dụng sau khi phân loại có kích thước là $10 \mathrm{~mm}$ đến $20 \mathrm{~mm}, 20 \mathrm{~mm}$ đến $40 \mathrm{~mm}$ dùng để thay thế hoàn toàn cốt liệu đá $1 \times 2$ trong bê tông truyền thống.

CLTC cho sản xuất bê tông cần đáp ứng yêu cầu về thành phần hạt và các chỉ tiêu kỹ thuật theo Tiêu chuẩn TCVN 11969:2018 [13]. Độ hút nước của hạt CLTC sau 5-10 phút là 5\%.

CLTC sử dụng được chia làm 3 loại: Cốt liệu ở trạng thái nguyên mẫu khô, cốt liệu được ngâm trong nước và cốt liệu được ngâm trong nước vôi trước khi trộn hỗn hợp bê tông.

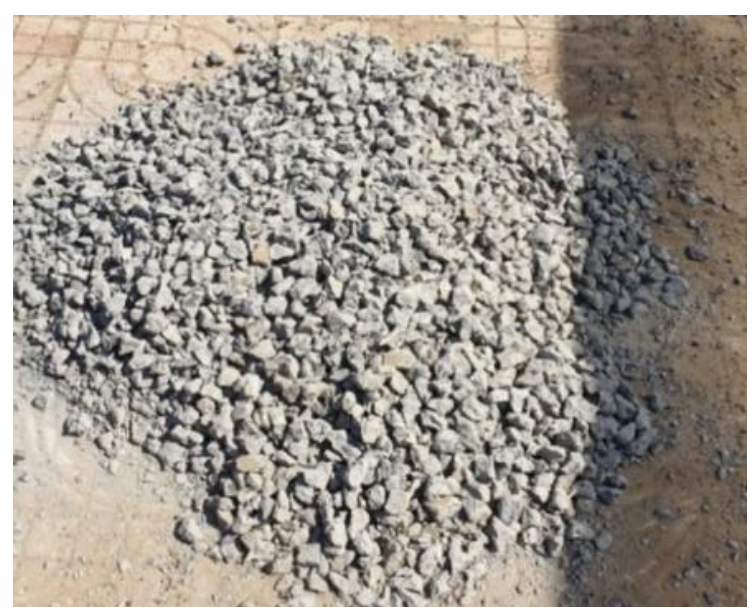

a) CLTC sau khi nghiền

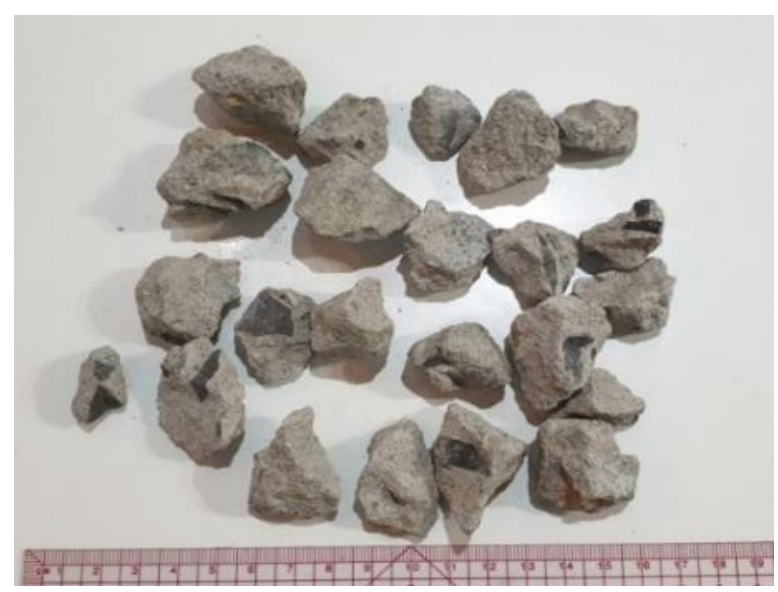

(b) CLTC sử dụng làm cốt liệu

Hình 2. Cốt liệu bê tông tái chế

\subsubsection{Một số loại vật liệu khác}

Nước được sử dụng để trộn bê tông thỏa mãn yêu cầu kỹ thuật theo Tiêu chuẩn quốc gia TCVN 4506:2012 - Nước cho bê tông và vữa Yêu cầu kỹ thuật. Ngoài ra, xi măng Hà Tiên PCB40, cát vàng và cốt liệu đá tự nhiên cũng được sử dụng để chế tạo các mẫu bê tông đối chứng.

\subsection{Thành phần cấp phối bê tông:}

Có 04 loại thành phần cấp phối bê tông sử dung trong nghiên cứu.

- Bê tông đối chứng sử dụng cốt liệu đá tự nhiên và xi măng truyền thống (ĐC) có cường độ chịu nén tiêu chuẩn sau 28 ngày quy đổi đạt mác M30.

- Bê tông geopolymer sử dụng CLTC ở trạng thái khô (BTCLK) thay thế hoàn toàn cốt liệu đá tự nhiên, và geopolymer thay thế hoàn toàn chất kết dính xi măng truyền thống.

- Bê tông geopolymer CLTC sử dụng CLTC ở trạng thái bão hoà nước (BTCLN) tương tự như mẫu BTCLK nhưng sử dung CLTC đã được ngâm nước.

- Bêtông geopolymer CLTC được ngâm trong nước vôi 1,5\% trong 7 ngày.

Trên cơ sở phương pháp thiết kế thành phần cấp phối bê tông theo nguyên tắc thể tích tuyệt đối, thành phần vật liệu của các hỗn hợp bê tông được nêu ở Bảng 3.

\subsection{Chế tạo mẫu bê tông và thí nghiệm nén một trục}

Hỗn hợp bê tông được lấy mẫu, chuẩn bị đúc mẫu dựa theo Tiêu chuẩn TCVN 3105: 1993 [14]. Mẫu xác định cường độ nén là tổ hợp 03 mẫu lập phương có kích thước 15x15x15 cm (Hình 3). Các mẫu bê tông được bảo dưỡng 48 giờ trong khuôn thép, sau đó, mẫu được tháo khuôn và tiếp tục bảo dưỡng trong phòng thí nghiệm đến các thời điểm $3,7,14$, 28, 56 ngày để làm thí nghiệm.

Các thành phần nguyên liệu sau khi được định lượng như tro bay, cát, đá được đưa vào máy trộn, nhào trộn khô trong khoảng 03 phút để tạo thành hỗn hợp bê tông khô. Tiếp đến, một nửa dung dịch hoạt hóa có tính kiềm được cho vào hỗn hợp bê tông khô và trộn đều khoảng 01 phút. Cuối cùng, bổ sung phần còn lại của dung dịch hoạt hóa kiềm, và tiếp tục trộn từ 03 đến 05 phút.

Trước khi đúc mẫu bê tông, hỗn hợp hợp bê tông tươi được xác định độ sụt bằng bộ dụng cụ chuyên dùng. Độ sụt của các mẫu bê tông geopolymer là $16 \mathrm{~cm}$. Lưu ý đây là độ sụt tối thiểu yêu cầu của bê tông geopolymer áp dụng trong thực tế [6].

Cường độ chịu nén của các mẫu được tiến hành nén mẫu theo Tiêu chuẩn TCVN 3118:1993 [15]. Cường độ chịu nén của mẫu bê tông được tính bằng công thức cho mẫu khối lập phương. 
Bảng 3. Thành cấp phối của các loại bê tông.

\begin{tabular}{|c|c|c|c|c|}
\hline \multirow{2}{*}{ Thành phần vât liệu $\left(\mathrm{kg} / \mathrm{m}^{3}\right)$} & ĐC & BTCLK & BTCLN & BTCLV \\
\hline & CLTN & CLTC khô & CLTC ngâm nước & CLTC ngâm nước vôi \\
\hline Xi măng PC40 & 350 & - & - & - \\
\hline Đá tự nhiên (10-20mm) & 1080 & - & - & - \\
\hline Cát & 720 & 720 & 720 & 720 \\
\hline Tro bay loại $\mathrm{F}$ & - & 350 & 350 & 350 \\
\hline CLTC & - & 1080 & 1080 & 1080 \\
\hline Dung dịch $\mathrm{NaOH} 10 \mathrm{M}$ & - & 50 & 50 & 50 \\
\hline Dung dịch $\mathrm{Na}_{2} \mathrm{SiO}_{3}$ & - & 125 & 125 & 125 \\
\hline Nước & 200 & 75 & 25 & 25 \\
\hline Tổng trọng lượng & 2350 & 2400 & 2350 & 2350 \\
\hline Độ sụt ( $\pm 1 \mathrm{~cm}$ ) & 12 & 16 & 16 & 16 \\
\hline
\end{tabular}

\section{Kết quả và thảo luận}

\subsection{Cường độ chịu nén}

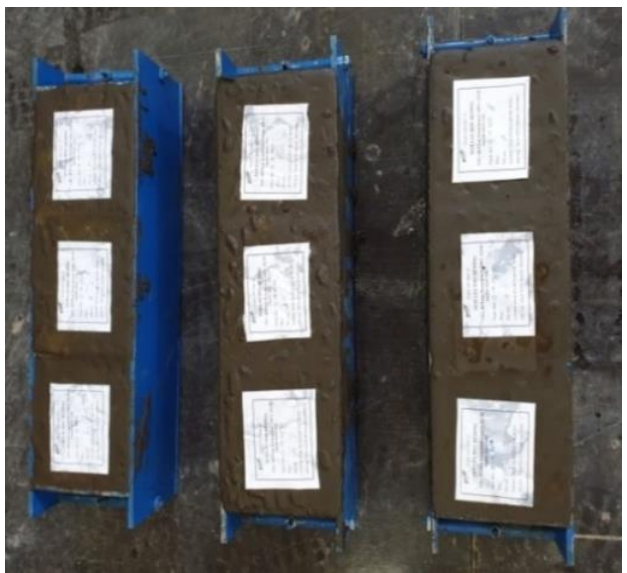

Hình 3. Mẫu bê tông 15x15x15 cm³ .

Kết quả cường độ chịu nén được trình bày trên Hình 4. Nhìn chung cường độ chịu nén của các loại bê tông đều tăng dần theo thời gian bảo dưỡng. So với mẫu bê tông đối chứng sử dụng xi măng và CLTN, các mẫu bê tông Geopolymer sử dụng 100\% CLTC cho kết quả cường độ chịu nén thấp hơn. Đối với mẫu BTCLK và BTCLN cường độ chịu nén chỉ đạt khoảng $26 \%$ đến $33 \%$ của mẫu ĐC sau 28 ngày (Hình 5). Điều này không quá ngạc nhiên vì các nghiên cứu trước đây đã chỉ ra rằng cường độ bê tông CLTC phụ thuộc rất nhiều vào cường độ của cốt liệu: do CLTC có độ rỗng lớn hơn, bề mặt CLTC có lớp vữa cũ bám dính có cường độ thấp, có thể có vết nứt trong hạt cốt liệu và xi măng cũ trong quá trình tái chế cốt liệu, do đó, bê tông CLTC có cường độ thấp hơn bê tông CLTN [5]. Các kết quả của mẫu BTCLV cho thây việc xử lý bề mặt cốt liệu bằng cách ngâm nước vôi đã cho cường độ chịu nén đạt trên $80 \%$ của mẫu ĐC sau 28 ngày bảo dưỡng (Hình 5 ). Điều này thể hiện hiệu quả tích cực của phương pháp xử lý CLTC này.

Hình 6 cho thấy sự phân bố hạt cốt liệu trong các mặt cắt bê tông là tương đối đồng đều, gồm cả các hạt CLTN, CLTN dính vữa cũ, các hạt cốt liệu là vữa cũ. Tuy nhiên mẫu bê tông sử dụng CLTC có cấu tạo rỗng xốp nhiều hơn so với bê tông xi măng sử dụng CLTN do có phần vữa cũ bám dính và phần đá xi măng cũ cũng có cấu tạo không đặc chắc. Điều này dẫn đến sự phá hủy trong mẫu bê tông Geopolymer CLTC chủ yếu xảy ra ở các vùng ITZ tiếp xúc giữa vữa cũ của hạt cốt liệu và vữa geopolymer tro bay mới.

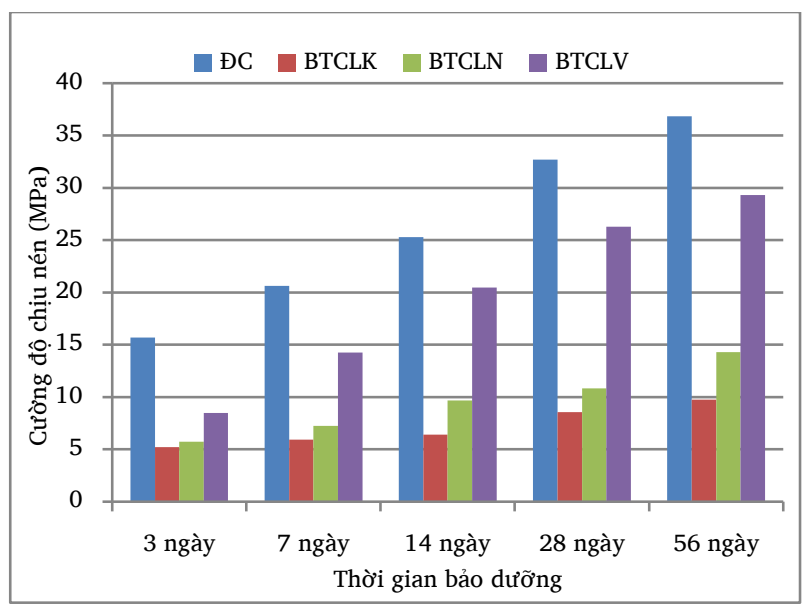

Hình 4. Cường độ nén của các mẫu bê tông theo thời gian.

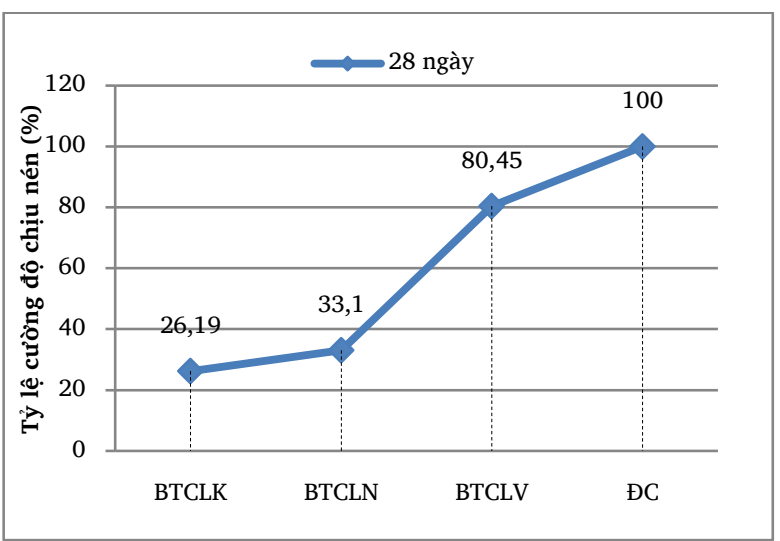

Hình 5. Tỷ lệ cường độ nén của các mẫu bê tông so với mẫu bê tông ĐC. 


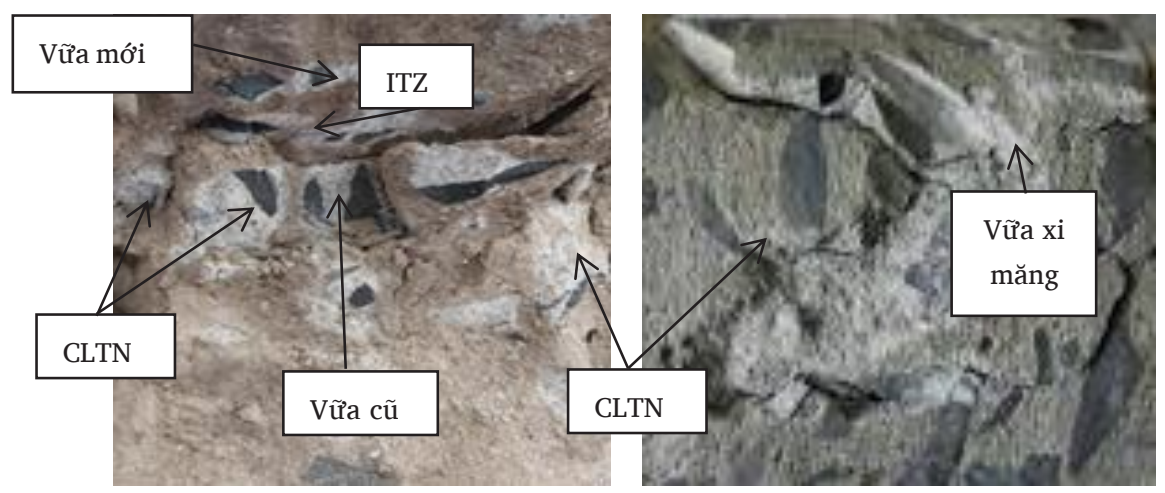

(a) Mẫu bê tông Geopolymer CLTC $\quad$ (b) Mẫu bê tông xi măng CLTN

Hình 6. Mặt cắt thành phần các loại bê tông.

\section{2. Ảnh hưởng của việc ngâm CLTC trong nước đến cường độ chịu nén}

Cường độ chịu nén của mẫu BTCLN cao hơn $21 \%$ so với mẫu BTCLK. Thật vậy, với bê tông geopolymer sử dụng CLTC khô, trong thời gian nhào trộn và trong thời gian đầu sau khi sản xuất mẫu, CLTC vẫn tiếp tục hút nước đến bão hòa, do đó, lượng nước tự do bị giảm đi, làm mất cân bằng lượng nước cần thiết để tạo ra geopolymer như dự kiến. Do đó, việc bão hòa nước CLTC trước khi trộn làm tăng cường độ chịu nén của bê tông geopolymer.

Hình 7 và Hình 8 cho thấy hạt CLTC có hình dạng góc cạnh, bề mặt nhám ráp, có nhiều thành phần bụi vữa vẫn bám dính bao quanh trên bề mặt hạt (Hình 7a), dẫn đến tăng độ hút nước và giảm cường độ của bê tông chứa CLTC khô. Trên ảnh chụp vi cấu trúc hạt CLTC đã được bão hòa nước (Hình 8), bụi vữa trên bề mặt cốt liệu đã giảm rõ rệt và xuất hiện các pha tinh thể (Hình $8 \mathrm{~b}$ ). Điều này có thể là do CLTC đã hút dung dịch kiềm hoạt hoá vào trong hạt cốt liệu, dẫn đến lượng dung dịch kiềm hoạt hoá không đủ để kích hoạt hoàn toàn các thành phần trong tro bay như dự kiến.

\section{3. Ảnh hưởng của việc ngâm CLTC trong nước vôi đến cường độ chịu nén}

Hình 9 chỉ ra hiệu quả của việc ngâm CLTC trong nước vôi trước khi chế tạo hỗn hợp bê tông Geopolymer: sau 28 ngày, thì cường độ chịu nén của mẫu BTCLV tăng từ 2,7 đến 3 lần So với các mẫu bê tông BTCLK và BTCLN sử dụng CLTC không qua xử lý ngâm nước vôi.

Hình 10 cho thấy tốc độ phản ứng của geopolymer thấp hơn so với xi măng Portland ở giai đoạn đầu: cường độ chịu nén của mẫu bê tông ĐC ở các độ tuổi sớm từ 3-7 ngày đạt 48-63\% cường độ ở 28 ngày tuổi, trong khi đó cường độ chịu nén của mẫu BTCLV chỉ đạt 32-54\% cường độ ở 28 ngày tuổi. Tuy nhiên, tốc độ phát triển cường độ của mẫu bê tông BTCLV ở khoảng thời gian 14 - 56 ngày là tương đương với mẫu bê tông ĐC.

Để đánh giá tính chất hạt CLTC ngâm nước vôi, nghiên cứu đã sử dụng phương pháp phân tích EDS thông qua hình ảnh bằng kính hiển vi điện tử quét (SEM).
Hình 11 cho thấy thành phần hóa học của hạt CLTC chứa một lượng lớn nguyên tố Si. Do đó, khi ngâm CLTC trong nước vôi thì phản ứng Pozzolan của $\mathrm{Si}$ với $\mathrm{Ca}(\mathrm{OH})_{2}$ có thể xảy ra:

$$
2 \mathrm{SiO}_{2}+3 \mathrm{Ca}(\mathrm{OH})_{2} \rightarrow 3 \mathrm{CaO} \cdot 2 \mathrm{SiO}_{2} \cdot 3 \mathrm{H}_{2} \mathrm{O}(\mathrm{C}-\mathrm{S}-\mathrm{H})
$$

Các liên kết C-S-H này được tạo ra, một phần lấp đầy các lỗ rỗng và làm đặc chắc hơn CLTC, từ đó dẫn đến tăng cường độ CLTC.

Ngoài ra, việc xử lý bão hòa nước vôi CLTC có thể nâng cao hơn nữa các đặc tính cơ học của vữa xi măng cũ bám trên bề mặt hạt CLTC. Canxi hydroxit bổ sung vào đã được đưa vào vữa, do đó nhiều canxi cacbonat, ettringite (Hình 12) được hình thành lắp đầy nhiều lỗ rỗng, dẫn đến cấu trúc vi mô đặc chắc hơn cho vữa xi măng cũ [16]. Giá trị mô đun đàn hồi và độ cứng của canxi cacbonat cao hơn giá trị của các sản phẩm thủy hóa xi măng [17]. Sự có mặt của $\mathrm{Ca}(\mathrm{OH})_{2}$ trên bề mặt của hạt CLTC là cầu nối liên kết chặt chẽ giữa CLTC và chất nền do phản ứng giữa $\mathrm{Ca}(\mathrm{OH})_{2}$ và $\mathrm{SiO}_{2}$ của tro bay tạo thành $\mathrm{C}-\mathrm{S}-\mathrm{H}$ và góp phần tăng cường độ mẫu ở tuổi dài ngày.

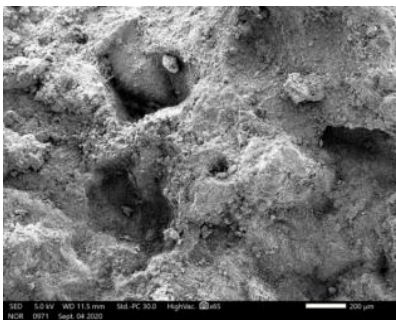

(a) Độ phóng đại 65 lần.

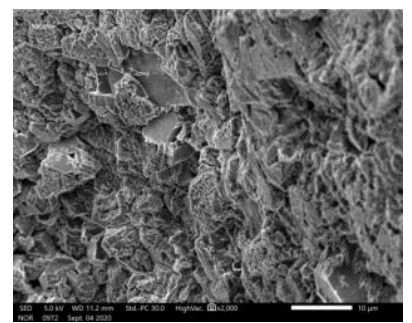

(b) Độ phóng đại 2000 lần
Hình 7. Vi cấu trúc SEM bề mặt vữa cũ CLTC ở trạng thái khô.

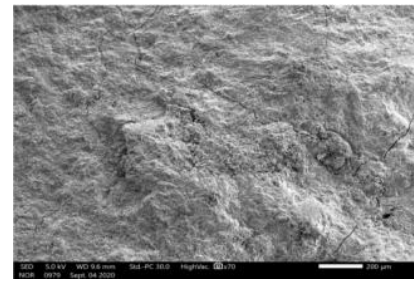

(a) Độ phóng đại 70 lần.

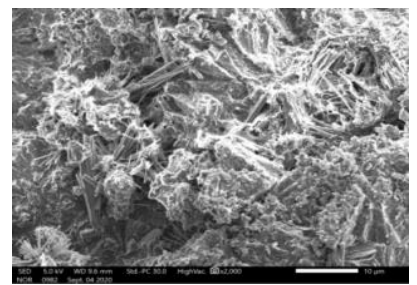

(b) Độ phóng đại 2000 lần
Hình 8. Vi cấu trúc SEM bề mặt vữa cũ CLTC đã bão hòa nước. 


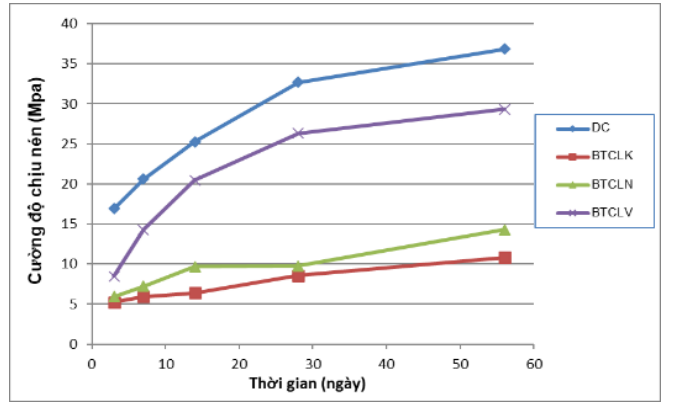

Hình 9. Sự phát triển cường độ nén của các mẫu bê tông theo thời gian.

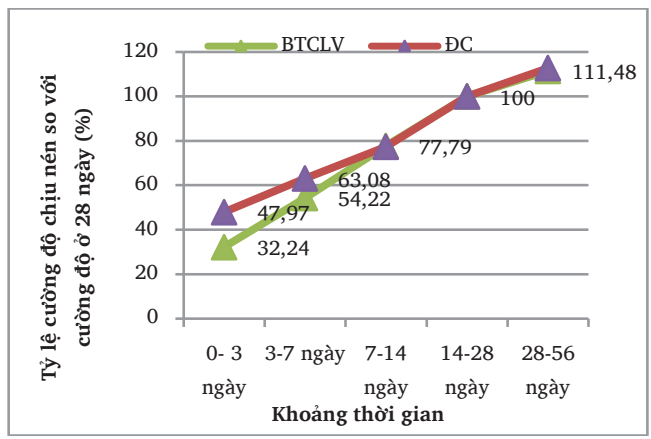

Hình 10. Tỷ lệ phát triển cường độ nén của bê tông BTCLV và bê tông ĐC trong các khoảng thời gian khác nhau.
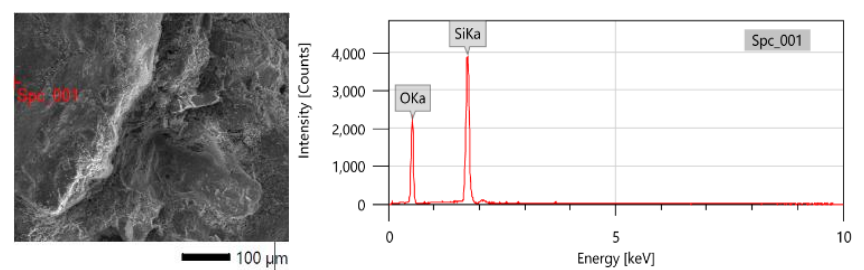

\begin{tabular}{|l|l|r|r|}
\hline \multicolumn{1}{|c|}{ Element } & \multicolumn{1}{c|}{ Line } & \multicolumn{1}{c|}{ Mass\% } & \multicolumn{1}{c|}{ Atom\% } \\
\hline $\mathrm{O}$ & $\mathrm{K}$ & $37.27 \pm 0.31$ & $51.06 \pm 0.43$ \\
\hline $\mathrm{Si}$ & $\mathrm{K}$ & $62.73 \pm 0.50$ & $48.94 \pm 0.39$ \\
\hline Total & & 100.00 & 100.00 \\
\hline Spc_001 & & & Fitting ratio 0.0296 \\
\hline
\end{tabular}

Hình 11. Phân tích EDS vùng bề mặt hạt CLTC khô.

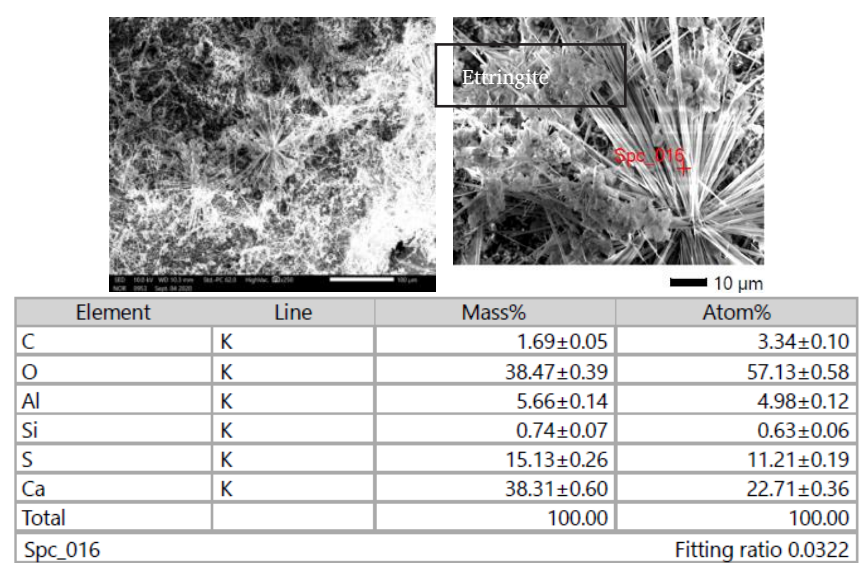

Hình 12. Phân tích EDS vùng bề mặt hạt CLTC sau khi ngâm nước vôi.

\section{Kết luận}

Việc tái chế các sản phẩm từ xây dựng và các phế phẩm từ nhà máy nhiệt điện là chủ đề quan trọng được quan tâm trong bối cảnh kinh tế tuần hoàn hiện nay. Bài báo trình bày nghiên cứu chế tạo bê tông Geopolymer sử dụng 100\% CLTC bảo dưỡng ở nhiệt độ môi trường. Nghiên cứu đánh giá tác động của việc xử lý CLTC bằng cách ngâm trong nước và trong nước vôi đối với cường độ chịu nén của Bê tông geopolymer sử dụng hoàn toàn CLTC.

Các mẫu bê tông Geopolymer sử dụng CLTC ngâm nước vôi đã có sự cải thiện rõ rệt về cường độ chịu nén: tăng 2,7 - 3 lần cường độ chịu nén của các mẫu sử dụng CLTC ở trạng thái khô tự nhiên hoặc được ngâm nước. Nguyên nhân của việc cải thiện cường độ được cho là phản ứng giữa các ion $\mathrm{SiO}_{2}$ có trong cốt liệu, tro bay và nước vôi, từ đó giúp cốt liệu được đặc chắc hơn, liên kết giữa cốt liệu và chất nền tốt, do đó cải thiện tính chất cơ học của CLTC.

Kết quả đạt được của nghiên cứu này là cơ sở để tiếp tục nghiên cứu thêm các tính chất khác của bê tông Geopolymer sử dụng 100\% CLTC ngâm trong nước vôi.

\section{Tài liệu tham khảo}

[1]. Bộ Xây dựng, "Ngành bê tông sẽ phải dùng cốt liệu tái chế thay thế đến $60 \%$ nguyên liệu thiên nhiên”, 2020. [Trực tuyến]. Địa chỉ: https://moc.gov.vn/tl/tin-tuc/62757/nganh-be-tong-se-phai-dung-cot-lieu-taiche-thay-the-den-60-nguyen-lieu-thien-nhien.aspx. [Truy cập 02/7/2020].

[2]. Hà Linh, "Thực trạng phát thải khí nhà kính ở Việt Nam", 2019. [Trực tuyến]. Địa chỉ: http:// ncif.gov.vn/Pages/NewsDetail.aspx?newid=21377. [Truy cập 02/7/2020].

[3]. B Bộ Công Thương, "Bộ trưởng Bộ Công Thương trả lời Đại biểu Trần Thị Hoa Ry, Đoàn Đại biểu Quốc hội tỉnh Bạc Liêu”, 2021. [Trực tuyến]. Địa chỉ: https:// moit.gov.vn/bo-cong-thuong-voi-quoc-hoi-va-cu-tri/bo-truong-bocong-thuong-tra-loi-dai-bieu-tran-thi-hoa-ry-do2.html. [Truy cập $15 / 7 / 2021]$.

[4]. Nguyên Hằng, "Tăng cường quản lý chất thải rắn”, 2017. [Trực tuyến]. Địa chỉ: http://tapchimoitruong.vn/phap-luat--chinh-sach-16/Tăng-cườngquản-lý-chất-thải-rắn-xây-dựng--18836. [Truy cập 01/12/2019].

[5]. Le Hoai Bao, Bui Quoc Bao, "Recycled aggregate concretes - a state-of-theart from the microstructure to the structural performance", Construction and Building Materials, Volume 257, 10 October 2020, 119522.

[6]. Le Hoai Bao, Bui Quoc Bao, Luping Tang, "Geopolymer recycled aggregate concrete: from experiments to empirical models", Materials 2021, 14, 1180.

[7]. Davidovits, J, "Properties of Geopolymer Cement", published in Proceedings first International conference on Alkaline Cements and Concretes, Scientific Reseach Institute on Binders an Materials, Kiev State Technical University, Kiev, Ukraine, 1994, 131-149.

[8]. Aissa Bouaissi, Long-yuan Li, Mohd Mustafa Al Bakri Abdullah, Quoc-Bao Bui, "Mechanical properties and microstructure analysis of FA-GGBSHMNS based geopolymer concrete", Construction and Building Materials, Vol. 210, 198-209, 2019.

[9]. K.Y. Ann, H.Y. Moon, Y.B. Kim, J. Ryou, "Durability of recycled aggregate concrete using pozzolanic materials". Waste Managemen, Vol. 28, 993-999, 2008.

[10]. Shi-cong Kou, Chi-sun Poon, Francisco Agrela, Comparisons of natural and 
recycled aggregate concretes prepared with the addition of different mineral admixtures, Cement \& Concrete Composites, Vol. 33, 788 - 795, 2011.

[11]. TCVN 10302:2014 - Phụ gia hoạt tính tro bay dùng cho bê tông, vữa xây và xi măng

[12]. A.M. Mustafa Al Bakri, H. Kamarudin, I. Khairul Nizar, M. Bnhussain, Y. Zarina, and A. R. Rafiza, "Correlation between $\mathrm{Na}_{2} \mathrm{SiO}_{3} / \mathrm{NaOH}$ Ratio and Fly Ash/Alkaline Activator Ratio to the Strength of Geopolymer". Advanced Materials Research, Vols. 341-342, 189-193, 2012. DOI:10.4028/www.scientific.net/AMR.341-342.189.

[13]. TCVN 11969:2018 - Cốt liệu lớn tái chế cho bê tông.
[14]. TCVN 3105: 1993 - Hỗn hợp bê tông nặng và bê tông nặng - Lấy mẫu, chế tạo và bảo dưỡng mẫu thử.

[15]. Tiêu chuẩn Việt Nam TCVN 3118:1993 - Bê tông nặng - Phương pháp xác định cường độ nén.

[16]. Zhan B.J., Xuan D.X., Poon C.S., "Enhancement of recycled aggregate properties by accelerated $\mathrm{CO} 2$ curing coupled with limewater soaking process", Cement and Concrete Composite, Vol. 89, 230 - 237, 2018.

[17]. J.I. Escalantea, L.Y. Gómez, K.K. Johal, G. Mendoza, H. Mancha, J. Méndez, "Reactivity of blast-furnace slag in portland cement blents hydrated under different conditions", Cement and Concrete Research, Vol 31, 1403 - 1409, 2001. 